\title{
Analyzing the Teaching and Learning of Mathematical Reasoning Skills in Secondary School
}

\author{
E. Elvis Napitupulu ${ }^{1}$ \\ ${ }^{1}$ Department of Mathematics, State University of Medan, Indonesia \\ Correspondence: E. Elvis Napitupulu. E-mail: elvisnapit@gmail.com
}

Received: October 5, 2017

Accepted: October 29, 2017

Online Published: November 28, 2017

doi:10.5539/ass.v13n12p167

URL: https://doi.org/10.5539/ass.v13n12p167

\begin{abstract}
The paper reports part of a study aimed at developing teaching materials in inculcating upper secondary students' mathematical reasoning skills (MRS). To develop the materials, the researcher implemented the Four-D Model. The study took subjects from five public schools in Province of North Sumatera, Indonesia. The researcher designed and developed students' work sheet (SWS) and instrument to measure MRS. Along the teaching ran, which applied problem-based learning model, the researcher observed teachers' and students' activities while nurturing and applying MRS in the frame of solving mathematical problems. Of the four indicators laid to measure the MRS, students lack most in use of pattern relationship to analyse situation, to make analogy, or to generalize. The ways support student's progress in achieving MRS are if (i) the problem faced is much mimicked the task solved in the classroom, (ii) more various problems given to solve under guidance, and (iii) intensive scaffolding is given.
\end{abstract}

Keywords: Analyzing, Teaching and Learning, Mathematical reasoning skills (MRS)

\section{Introduction}

Appealing for making higher order thinking the ultimate goal as the outcome of mathematics education had been launched since eighties (Branca, 1980; NCTM, 1989; National Research Council, 1989; Resnick, 1987; Schöenfeld, 1985). On one side, schools should prepare students to live in the twenty first century, which predicted to be full of uncertainty and bounded natural resources. To be survive, they should be smart, that is capable and competent in higher order thinking such as reasoning, logical, critical, and creative in the frame of problem solving. On the other side, they should have, to some extent, perseverance, self-regulated learning, self-efficacy, and positive attitude to doing mathematics. Being smart and having good character, they become productive citizens.

If students are to learn mathematics, it is far from enough just asking them to memorize formula and to apply procedures, but they should be also able to reason or to think critically and creatively ( Minarni \& Napitupulu, 2017). Stein, Grover, and Henningsen (1996) emphasize that it should stress on students' full understanding of mathematics, which consists of more than knowledge of mathematical concepts, principles, and their structure. The writers continued that mathematics educators and philosophers had convincingly argue that full understanding includes the capacity to engage in the processes of mathematical thinking, in essence doing what makers and users of mathematics do: framing and solving problems, looking for patterns, making conjectures, examining constraints, making inferences from data, abstracting, inventing, explaining, justifying, challenging, and so on. In a similar manner, Romberg (1992) stated students should not view mathematics as a static, bounded system of facts, concepts, and procedures to be absorbed but, rather, as a dynamic process of "gathering, discovering and creating knowledge in the course of some activity having a purpose" (p. 61). To sum up, learning mathematics should push up to doing mathematics in which learners solve problems by applying their understanding and reasoning.

Reasoning is the primary and continuously tool one employs when trying to understand mathematics or to solve problems in mathematics. Since in reasoning, one attempts to relate facts, concepts, or principles one into another; looks for pattern emerged and makes effort to generalize or logical conclusion, and makes conjecture and simultaneously its proof (NCTM, 2000; O’Daffer \& Thornquist as cited in Artzt \& Yaloz-Femia, 1999). By relating objects and/or draw logical conclusion, one builds his understanding on the problem posed. He then apply his understanding and reasoning to solve problem he faces. To sum up, understanding triggers reasoning take place and in turn by reasoning, one improves his understanding. The process occurs cyclically. This shows mathematical reasoning is essential and at the heart of understanding and problem solving processes.

Researchers have paid much attention to reveal students' mathematical reasoning and proving proficiency in different countries and they found that students face serious difficulties when working in this domain (Stylianides, 2009). TIMSS reported similar result for fourth and eighth grade students (Mullis, et. al, 2012). In the same report, Indonesian eighth graders only achieved $17 \%$, which is equivalent to score 388 ; meanwhile international average was $30 \%$ equivalent to score 465. For upper secondary school, Napitupulu, Suryadi, \& Kusumah (2016) reported students' MRS in PBL classroom was 39\% while in the conventional one was 33\%. Students lack most at give explanation on model, 
fact, properties, relationship, or pattern exists. The low achievement indicates that treatment should take place to overcome the problem.

Despite the low achievement, Bieda (2010) found it still know very little about how skills related to justifying and proving are taught in school mathematics - particularly in mathematics courses outside of high school geometry. She further asserted:

Research has not examined students' opportunities to develop deductive reasoning and to learn skills for evaluating the validity of others' mathematical arguments. Without such opportunities, students are inadequately prepared to participate in meaningful discussions about mathematical proofs and to explore the variety of roles a proof can play in doing mathematics... To understand how to change the ways in which students learn to prove in school mathematics communities, we need to understand how teachers, students, and the curricula they use elements existing at the nexus of school mathematics communities - interact in classroom settings when students are discussing and developing justifications and proof.

Concerning to the statement Bieda posed, this study attempted to nurture and facilitate students to develop their mathematical reasoning skills by means of solving problems. Doing so, they have chances discussing the validity of arguments they construct and relating knowledge and experiences to gain deep understanding.

\subsection{Mathematical Reasoning Skills}

As asserted earlier, to understand or to solve problem in mathematics, the primary and main tool one make use is reasoning. It is important to note, Lithner (2000) emphasizes that reasoning is the foundation of mathematics (p. 165). He continues arguing that if reasoning ability is not developed in the student then mathematics simply becomes a matter of following a set of procedures and mimicking examples without thought as to why they make sense. If this is the case, it would certainly lead students considering mathematics as a boring subject and something nothing to do with and the ultimate goal of learning mathematics would be put aside accordingly.

The study referred to Lithner definition on reasoning i.e. as the line of thought, the way of thinking, adopted to produce assertions and reach conclusions. The reasoning concerns the transfer of properties from one familiar situation to another (task solving) situation that has at least superficial resemblance to the familiar situation (p.167). Whereas argumentation is the substantiation, the part of the reasoning that aims at convincing oneself, or someone else, that the reasoning is appropriate (p.166).

The study grounded its framework on the work of Lithner (2003). The author classifies reasoning into plausible reasoning (PR), established experience (EE), and identification of similarity (IS). This classification based on three parts, which he called reasoning structure, components and properties, and reasoning characteristics (p.31). According to Lithner, one way to structure the reasoning is:

1. A problematic situation is met where it is not obvious how to proceed.

2. Strategy choice: Try to choose (in a wide sense: choose, recall, construct, discover, etc.) a strategy that can solve the difficulty. This choice can be supported by predictive argumentation: Will the strategy solve the difficulty?

3. Strategy implementation: This can be supported by verificative argumentation: Did the strategy solve the difficulty?

4. Conclusion: A result is obtained, (p.31-32).

A sequence of mathematical reasoning is classified as PR if strategy choice and strategy implementation: (i) is founded on intrinsic mathematical properties of the components involved in the reasoning, and (ii) is meant to guide towards what probably is the truth, without necessarily having to be complete or correct. Meanwhile, the reasoning is classified as EE if the argumentation (i) is founded on notions and procedures established on the basis of the individual's previous experiences from the learning environment, and (ii) is meant to guide towards what probably is the truth, without necessarily having to be complete or correct. Last, the reasoning is classified as IS if it fulfils (i) the strategy choice is founded on identifying similar surface properties in an example, theorem, rule, or some other situation described earlier in the text. (ii) The strategy implementation is carried through by mimicking the procedure from the identified situation.

Based on the work of Napitupulu, Suryadi, \& Kusumah (2016), the study laid four indicators to measure students' MRS, that is to say: (a) Draw logical conclusion; (b) Give explanation on model, fact, properties, relationship, or pattern exists; (c) Make conjecture and proof; and (d) Use of relationship pattern to analyse situation, to make analogy, or to generalize.

\subsection{Problem-Based Learning}

One of model of teaching that promote students engagement in building new knowledge based on previous knowledge and experiences is problem-based learning (PBL). PBL is an instructional method in which students learn through solving problems and reflecting on their experiences (Barrows \& Tamblyn, 1980). According to Barrows (1996), there are six characteristics of PBL, i.e. (i) learning is student-centered, (ii) learning occurs in small group, (iii) teacher is facilitator or guider, (iv) problem forms the organizing focus and stimulus for learning, (v) problem is a vehicle for the development of problem solving skill, (vi) new information is acquired through self-directed learning. Considering the characteristics, it is obvious that PBL demand the learners to be active and self-directed with enough previous 
knowledge and experience to doing mathematics, especially solving problems by exploiting and exploring their reasoning skills.

Hmelo-Silver and Barrows (2006) emphasize, in PBL, students have the opportunity to develop skills in reasoning and self-directed learning. PBL requires students to become responsible for their own learning. The PBL teacher is a facilitator of student learning, and his interventions diminish as students progressively take on responsibility for their own learning processes. (p.24). Consequently, students who are not accustomed to learning collaboratively, self-directed, solving problem, and do not have perseverance usually feel inconvenient and refuse learning in such a way. In this case, to assure PBL run as it should be teacher-facilitator should take role more to motivate, scaffold, direct, and control students learning. This is also stressed in Collins, Brown, \& Newman (1989), "the facilitator guides students in the learning process, pushing them to think deeply, and models the kinds of questions that students need to be asking themselves, thus forming a cognitive apprenticeship". For students new to PBL, role of teacher-facilitator is key and critical. Students, who are stuck in effort to solving problem, should immediately addressed for helping. Hmelo-Silver and Barrows (2006) argued:

Facilitators make key aspects of expertise visible through questions that scaffold student learning through modelling, coaching, and eventually fading back some of their support. In PBL, the facilitator is an expert learner, able to model good strategies for learning and thinking, rather than providing expertise in specific content. This role is critical, as the facilitator must continually monitor the discussion, selecting and implementing appropriate strategies as needed. As students become more experienced with PBL, facilitators can fade their scaffolding until finally the learners adopt much of their questioning role.

\subsection{Research Questions}

The study intended to answer these subsequent questions:

(Q1) In what task did students most fail and in what task did they succeed? How did the learning process predict that phenomenon?

(Q2) In what ways did the learning process support students' progress in achieving the MRS?

\section{Methodology}

The research is developmental in nature. Subjects were students from five A-rank public upper secondary schools from each one classroom is taken. Five regular teachers in each classrooms taught during the research and the researcher and one other teacher observed while the teaching and learning processes proceed. The researcher administered pretest and posttest, which consisted of four problems for each, derived from four indicators mentioned earlier to measure students' MRS. The researcher applied the holistic rubric scoring to assess students' work on MRS (Table 1).

Table 1. Holistic Rubric for Scoring Students' MRS

\begin{tabular}{l} 
Criteria \\
Solution is correct and complete. Reasoning in solving problem and its communication are complete. Adequate \\
explanation on the solution, contain a little defect. \\
Solution is correct. Good reasoning in solving problems and its communication. Explanation on the solution exists \\
though contain some defect. \\
Complete solution does not emerge. Adequate reasoning in solving problems and its communication. Defect 2 \\
reasoning emerge clearly. Inaccurate conclusion. Limited understanding on mathematical concept. \\
Problem emerges while imitating mathematical idea and unable to develop. Lack of reasoning and its \\
communication. A lot of incorrect calculation emerge. \\
No solution exist. No reasoning in solving problem. Neither mathematical understanding nor response on \\
possibilities emerges. Just guessing. \\
\hline The teachers conducted lessons for four meetings. SWS 1 contains nine problems and needed two meetings to \\
complete. At the first lesson, the teacher oriented each group to work on problems in the previous part or SWS 1 . The \\
problems in SWS 1 were intended to inculcate the ability in drawing logical conclusion and give explanation on model, \\
fact, properties, relationship, or pattern exists, and use of relationship pattern to analyse situation, to make analogy, or \\
to generalize. Tasks in SWS 1 constitute establishing trigonometric comparison in the four quadrants of Cartesian \\
plane and related angles and apply it to solve related problems. SWS 2 contains six problems, which is intended to \\
inculcate students' skill in all the four indicators mentioned earlier. The last SWS contained five problems. Similar to \\
SWS 2 , all of the problems in SWS 3 pursuit the four indicators mentioned above. All tasks are based on sine rule. \\
SWS 2 and 3 each needed one meeting. The tasks were adopted from Sinaga, et al (2014) textbook and book of Thong \\
and Hiong (2006). While conducting lesson, the teachers gave scaffolding and nurtured students, either classically or \\
in-group, to solve problems. The collected data then were analysed quantitatively and qualitatively.
\end{tabular}

\section{Results and Discussion}

\subsection{Students' Performance on MRS Test}

There were four problems posed to measure students' performance on MRS either pre-test or post-test. Pretest problems are about exponent, basic trigonometry, matrix, and system of linear equation of two variables. The students 
have already learned all of the materials before tested. Meanwhile, the posttest problems are about trigonometric comparison of related angles, trigonometric identity, and cosine rule. Table 2 showed the distribution of pre and posttest problems into each RMS indicator. Table 3 showed each indicator with its related problem. Since problem number 1 and 2 simultaneously measure both indicator 1 and 2, they are put in the same box. Table 4 presents percentage of students' achievement on the both tests refer to holistic rubric of scoring for each problem. Score zero up to two means underperformed and score three or four means performed. To say differently, score zero up to fifty means underperformed and more than fifty up to one hundred means performed in 100-scale.

Table 2. Blue Print of RMS Indicators and Related Pre and Posttest Problems

\begin{tabular}{ccc}
\hline Indicator & \multicolumn{2}{c}{ Problem number } \\
\cline { 2 - 3 } & Pre test & Post test \\
\hline Draw logical conclusion $\left(\mathrm{I}_{1}\right)$ & 1 & 1 and 2 \\
Use of pattern relationship to analyse situation, to make analogy, or to generalize $\left(\mathrm{I}_{2}\right)$ & 2 & 1 and 2 \\
Make conjecture and proof $\left(\mathrm{I}_{3}\right)$ & 4 & 3 \\
Give explanation on model, fact, properties, relationship, or pattern exists $\left(\mathrm{I}_{4}\right)$ & 3 & 4 \\
\hline
\end{tabular}

Table 3. RMS Indicators and Its Related Problem

\begin{tabular}{ll}
\hline Indicator & Problem \\
\hline 1. Draw logical conclusion. & $\begin{array}{l}\text { 1. Let } x=\sin \theta-2 \cos \theta \text { and } y=2 \sin \theta+\cos \theta \text {. Determine } \sin \theta \\
\text { and } \cos \theta \text { in } x \text { and } y . \text { Then establish relationship berween } x \text { and }\end{array}$ \\
$\begin{array}{ll}\text { 2. Use of pattern relationship to analyse situation, } \\
\text { to make analogy, or to generalize. }\end{array}$ & $\begin{array}{l}\text { 2. Look at } \triangle A B C \text { below. Explain why } \sin \angle A<1 \text {, and } \sin \angle A< \\
\tan \angle A \text { ? }\end{array}$
\end{tabular}

3. Make conjecture and proof.

3. Look at $\triangle A B C$ below. $C D$ is one of its height. By using sine for $\angle A$, determine the area of the triangle. What is the formula if you use $\angle B$ ? What if $\angle C$ ? Prove your answer.

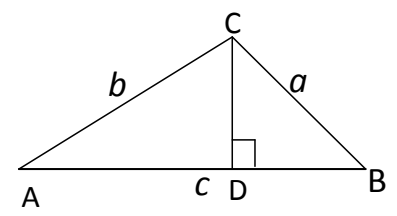

4. Give explanation on model, fact, properties, 4. Verify that $\tan \theta-\operatorname{cosec} \theta \sec \theta\left(1-2 \cos ^{2} \theta\right)=\cot \theta$. relationship, or pattern exists.

Table 4, for posttest, tells us that the students were most succeed in task "Make conjecture and proof" (problem 3). They were less succeed in task "Give explanation on model, fact, properties, relationship, or pattern exists "(problem 4). On the contrary, for pretest, they exactly were worst in those tasks. At the other side, for pretest, nearly half of them succeed on tasks 1 and 2 but for posttest, they were totally failed. This is undoubtedly contradictive.

Actually, some tasks in SWS 1 and 2 had facilitated students to establish a relationship between two variables when a pair of equations given. While working on the tasks, their teachers helped by giving scaffolding at many occasions. It was hard for them to discover the way to connect terms contained in the equations. Furthermore, they failed to recognize what algebraic operation should take place to make it closer to the goal. The result the students achieved in this case was predicted by their work on problems of the SWS. The discrepancy between their achievement in the pretest and the posttest looked due to not only the mathematical content but also the lack of experiences in handling such problems.

From Figure 1, it is readily seen, the student make use his establish experience in handling system of linear equation and applying the substitution method and it works. Therefore, it is an EE category. Unfortunately, he was unable to continue working to establish the relationship between $x$ and $y$. Most of the students did similar work. 
Table 4. Students' Performance in Percentage on MRS for Both Pre and Posttest

\begin{tabular}{|c|c|c|c|c|c|c|c|c|c|c|c|c|}
\hline \multirow{2}{*}{ Problem } & \multirow{2}{*}{ Performed Pre/Post } & \multirow{2}{*}{ Under performed Pre/Post } & \multicolumn{5}{|c|}{ Pretest Score (\%) } & \multicolumn{5}{|c|}{ Posttest Score (\%) } \\
\hline & & & 4 & 3 & 2 & 1 & 0 & 4 & 3 & 2 & 1 & 0 \\
\hline 1 & $44 / 2$ & $56 / 98$ & 44 & 0 & 13 & 27 & 16 & 0 & 2 & 23 & 21 & 54 \\
\hline 2 & $46 / 5$ & $54 / 95$ & 30 & 16 & 2 & 43 & 9 & 5 & 0 & 53 & 9 & 33 \\
\hline 3 & $2 / 64$ & $98 / 36$ & 2 & 0 & 0 & 7 & 91 & 23 & 41 & 34 & 0 & 2 \\
\hline 4 & $0 / 30$ & $100 / 70$ & 0 & 0 & 0 & 4 & 96 & 30 & 0 & 23 & 3 & 44 \\
\hline
\end{tabular}

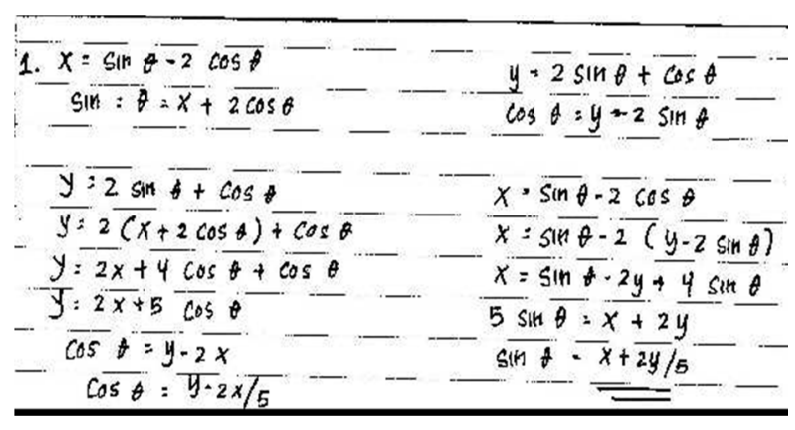

Figure 1. Student Sample Work on Problem 1

One work on problem 2 is shown in Figure 2. This work tells us the type of reasoning the student used is PR. The strategy he chose and implemented based on intrinsic mathematical properties of the component involved but it did not lead him to the solution. He even then wrote something nonsense and remained in a problematic situation. In this case, he actually should take advantage of the familiar situation (right triangle) and establish the trigonometric comparison (EE). He can then combine the definition of sine, tan, and Pythagoras to solve the problem.

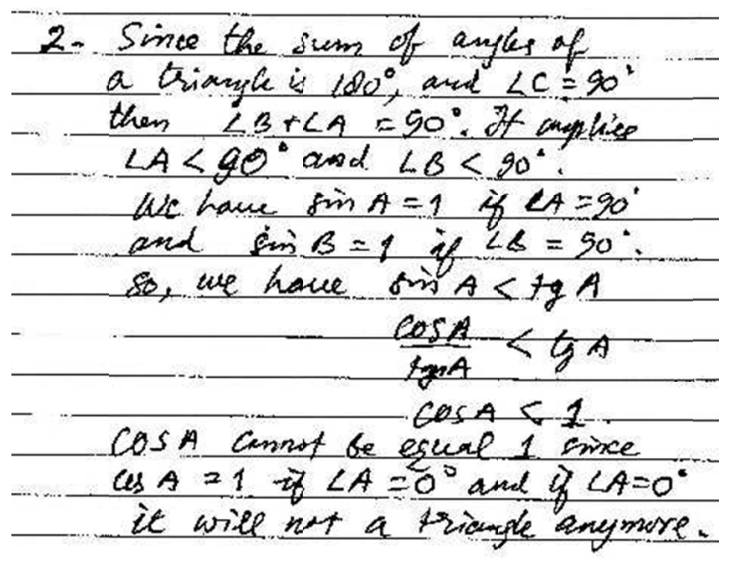

Figure 2. Student Sample Work on Problem 2

The students were most successful at task "make conjecture and proof". Problem 3 facilitated them to accomplish the work, though not completely. It is clear from Figure 3, they face a familiar situation, that is finding the area of a triangle. This procedure then combined with trigonometric comparison to finish the work. Unfortunately they were unaware their work was not finished yet. This is an EE reasoning.

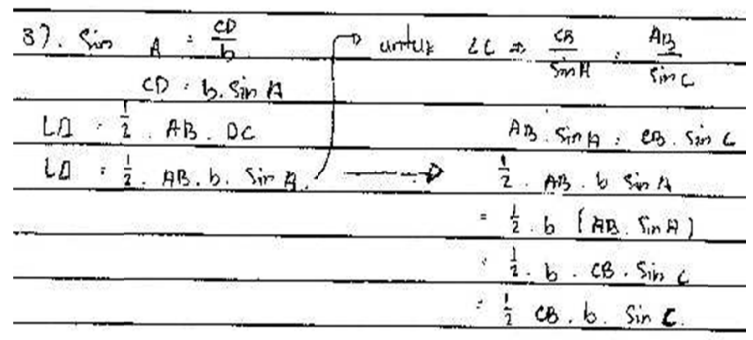

Figure 3. Student Sample Work on Problem 3 


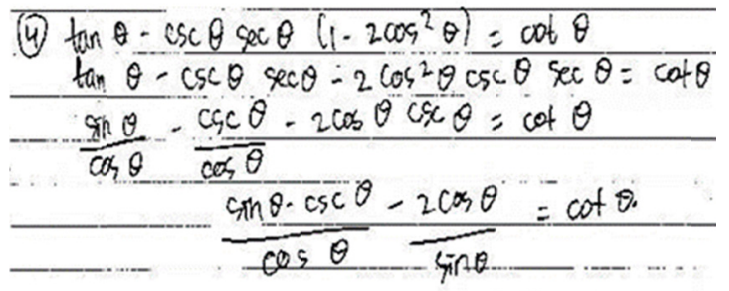

Figure 4. Student Sample Work on Problem 4

For the last task, the students employed IS. They mimicked procedure from the identified situation (Figure 4). However, it is not suffice. The fault committed algebraically (distributive) make them more difficult to apply procedure in effort to make the situation simpler toward solution. Therefore, they remained in a problematic situation and could not reach the solution.

Along the learning processes, students worked to solve various problems on trigonometric comparison and functions. SWS 2 problem number 1 and 5 trained them to achieve sepecially skill in $\mathrm{I}_{4}$. Problem number 4 in SWS 3 is relatively equivalent in difficulty to problem 4 in the post-test in establishing a relationship between $x$ and $y$. Neither one of them was able to accomplish the task in the SWS nor in the posttest. Therefore, students' inability to accomplish the task completely was predicted from their work on this indicator.

Problem 3 of the post-test is exactly a repetition. It was a problem in SWS 3. The result was an image of their work while handling the tasks in the teacher and learning process. SWS 1 problem number 9, SWS 3 problem 2 and 3 support indirectly to accomplish problem 2 of the post-test to grasp $I_{1}$ and $I_{2}$ competencies. Their work on these problems was better than it was on the post-test. Although at the beginning they start well, but the failure to recognize a familiar situation in hand, made them go unintentionally. Therefore, at this task, most of them only achieved one fourth of the maximum score and it was classified underperformed. SWS 1 problem number 8, SWS 2 problem number 3,4 , and 6 , and SWS 3 problem number 4 support problem 1 of the post-test to achieve $I_{1}$ and $I_{2}$. Their work on these SWS problem really illustrated what they would do on the post-test.

Albeit little, overall the intervention, which took four courses time to accomplish, has successfully improve students MRS. During conducting the lessons, teachers have played their role as facilitator-guider in much occasion, though not optimal. Some of them have followed training how to implement teaching model based on constructivism. However, they very rarely use it in their classrooms. Consequently, they could not conduct the lesson fluently as it should be. For example, the scaffolding they gave was inappropriate to the situation emerged or the scaffolding itself did not emerge. In addition, observation revealed too many groups in the classroom made teachers difficult to give help optimally. Moreover, students' lack of understanding on basic knowledge relating to the tasks, such as Pythagorean properties, algebraic operation, and algebraic properties became other barriers to accomplish the tasks. Besides, their understanding on trigonometric comparison is not firmed yet. As consequence, they were not easily and fast move on to the deeper and challenging task such as posed in the study.

Similar result also obtained in a study of Bieda. She investigated the process and outcome of implementing proof-related tasks in the classroom. She found that students' experiences with such tasks are insufficient for developing an understanding of what constitutes valid mathematical justification. She even showed that in the best of circumstances - teachers with ample experience and professional development using a curriculum that provides multiple opportunities for justification and proof - instruction that supports students' understanding of justification and proof at the middle school level is quite superficial. She continued with suggestion that greater emphasis is needed for middle school teacher preparation, professional development, and curricular support to make justifying and proving a routine part of middle school students' opportunities to learn.

\section{Conclusion}

Of the four indicators laid to measure the MRS, students lack most in use of pattern relationship to analyse situation, to make analogy, or to generalize. On the other hand, they most succeed in make conjecture and proof. Either successfulness or failure of the students in accomplishing the post-test was illustration of their work on SWS problems. Moreover, The ways support student's progress in achieving MRS are if (i) the problem faced is much mimicked the task solved in the classroom, (ii) more various problems given to solve under guidance, and (iii) intensive scaffolding is given.

\section{Acknowledgments}

This research was supported by the Ministry of Research, Technology and Higher Education of the Republic of Indonesia. The author is thankful to Rector of Universitas Negeri Medan, Research Director, and Dean of Faculty of Mathematics and Natural Sciences for providing necessary facilities to conduct the research. 


\section{References}

Artzt, A. F. \& Yaloz-Femia, S. (1999). Mathematical Reasoning during Small-Group Problem Solving. In L.V. Stiff (Ed). Developing Mathematical Reasoning in Grade K-12. Reston,VA: NCTM.

Barrows, H. S. (1996). Problem-Based Learning in Medicine and Beyond: A Brief Overview. New Direction for Teaching and Learning, No. 68, Winter.

Barrows, H. S. and Tamblyn, R. (1980). Problem-based learning: An approach to medical education. New York: Springer.

Bieda, K. N. (2010). Enacting Proof-Related Tasks in Middle School Mathematics: Challenges and Opportunities. Journal for Research in Mathematics Education, 41(4), 351-382. DOI: 10.2307/41103880.

Branca, N.A. (1980). Problem Solving as a Goal, Process, and Basic Skill. In S. Krulik (Ed). Problem Solving in School Mathematics. 1980 Yearbook. Reston, VA: NCTM.

Collins, A., Brown, J. S., \& Newman, S. E. (1989). Cognitive apprenticeship: Teaching the crafts of reading, writing, and mathematics. In L. B. Resnick (Ed.). Knowing, learning, and instruction: Essays in honor of Robert Glaser (pp. 453-494). Hillsdale NJ: Erlbaum.

Hmelo-Silver, C. E., \& Barrows, H. S. (2006). Goals and Strategies of a Problem-based Learning Facilitator. Interdisciplinary Journal of Problem-Based Learning, 1(1). http://dx.doi.org/10.7771/1541-5015.1004.

Lithner, J. (2000). Mathematical reasoning in school tasks. Educational Studies in Mathematics, 41(2), $165-190$. https://doi.org/10.1023/A:1003956417456.

Lithner, J. (2003). Students' Mathematical Reasoning in University Text Book Exercises. Educational Studies in Mathematics, 52: 29-55. https://doi.org/10.1023/A:1023683716659.

Minarni, A. \& Napitupulu, E. E. (2017). Developing Instruction Materials Based on Joyful PBL to Improve Students Mathematical Representation Ability. International Education Studies, 10(9), 23-38. https://doi.org/10.5539/ies.v10n9p23.

Mullis, I. V. S. et al. (2012). TIMSS 2011 International Result in Mathematics. Boston, MA: TIMSS and PIRLS International Study Center.

Napitupulu, E.E., Suryadi, D., \& Kusumah, Y.S. (2016). Cultivating Upper Secondary Students' Mathematical Reasoning Ability and Attitude towards Mathematics through Problem-Based Learning. Journal on Mathematics Education, 7(2), 61-71. http://dx.doi.org/10.22342/jme/.7.2.3542.117-128.

National Council of Teachers of Mathematics. (1989). Curriculum and evaluation standards for school mathematics. Reston, VA: NCTM.

National Research Council. (1989). Everybody counts. Washington, DC: National Academy of Sciences.

National Council of Teachers of Mathematics. (2000). Principles and Standards of School Mathematics. Reston, VA: NCTM.

Resnick, L. B. (1987). Education and Learning to Think. Washington DC: National Academic Press

Romberg, T. A. (1992). Perspectives on scholarship and research methods. In D. A. Grouws (Ed.). Handbook of research on mathematics teaching and learning (pp. 49-64). New York: Macmillan.

Schöenfeld, A. H. (1985). Mathematical Problem Solving. Orlando: Academic Press, Inc.

Sinaga, B. et. al. (2014). Buku Matematika Kelas X SMA-Untuk Siswa. Jakarta: Kementerian Pendidikan dan Kebudayaan Republik Indonesia.

Stein, M. K., Grover, B. W., and Henningsen, M. (1996). Building Student Capacity for Mathematical Thinking and Reasoning: An Analysis of Mathematical Tasks Used in Reform Classrooms. American Educational Research Journal, 33(2), 455-488. https://doi.org/10.3102/00028312033002455.

Stylianides, G. J. (2009). Reasoning-and-Proving in School Mathematics Textbooks. Mathematical Thinking and Learning, 11(4), 258-288, DOI: 10.1080/10986060903253954

Thong, H. S. \& Hiong, K. N. (2006). New Additional Mathematics (3rd ed.). Singapore: SNP Panpac Pte Ltd.

\section{Copyrights}

Copyright for this article is retained by the author(s), with first publication rights granted to the journal.

This is an open-access article distributed under the terms and conditions of the Creative Commons Attribution license (http://creativecommons.org/licenses/by/4.0/). 